\title{
ИДЕОЛОГИЯ СОЦИУМА: ИСТОКИ И РЕАЛЬНОСТЬ
}

\section{О.И. Заздравнова, А.П. Заздравнов}

В современной философской, социологической и политологической литературе понятие идеологии рассматривается в двух аспектах. Чаще всего об идеологии говорят как о сфере общественного сознания, ориентированной исключительно на переработку всех накопленньх знаний, в том числе входящих в различные формы общественного сознания, отражающих общественное бытие. Но не менее распространено понимание идеологии как теоретического выражения коренных интересов классов, социальных групп, представленного в виде целей, оценок и установок. Иначе говоря, идеология понимается как классовая (социально-групповая) доктрина. Правда, в последнее время утверждается иное понимание идеологии, связанное с выявлением ее социальной функции. Так, в работах О. Лемберга и Н. Лумана идеология однозначно трактуется как исторически обусловленное средство социокультурной ориентации человека (см.: [6], [7]).

Появление идеологии связано с вычленением из содержания наличных форм общественного сознания нормативных ориентаций, что позволяет индивиду самоопределяться в системах социальных связей, а человеческое отношение к миру структурировать как основную функцию социального бытия. Благодаря этому в вещах и явлениях окружающего мира выделяются те стороны, которые могут быть подвержены актуализации со стороны индивида: «это не просто предметная и социальная действительность или конкретные события и обстоятельства жизни личности. . . Этот мир есть та же самая предметная и социальная действительность, но действительность, рассмотренная как совокупность актуальностей личной жизни» [4, с. 17]. Таким образом, 
идеологическое сознание является такой формой регуляции жизнедеятельности личности, которая становится ее саморегуляцией, самоопределением, т. е. системой убеждений по кардинальным вопросам социального бытия. Здесь находятся истоки органической связи личностного с общественным.

В конечном же счете идеология, как и все общественное сознание, отражает общественное бытие под ценностным углом зрения и на этой основе вырабатывает исходные позиции определенной социальной группы и установки коллективного сознания по отношению $\mathrm{k}$ конкретным социальным реалиям. Поэтому содержание идеологии это не просто отраженное общественное бытие, а отраженное в ценностном ракурсе, в определенном сцеплении, соподчинении внутренних элементов сознания, в их особой смысловой значимости. Вот почему современный мир является в одинаковой степени объектом отражения в различных идеологических системах, но тем не менее внутреннее идейное и ценностно-ориентированное содержание этих систем существенно различно.

Э. Дюркгейм в свое время отмечал, что категории знания в значительной степени определяются структурой социальных групп и отношений и варьируются вместе с изменениями в общественной организации (см.: [2]). Такая функциональная связь знания со структурой общественных отношений содержит в себе «покушение» на объективный гносеологический смысл человеческой мысли именно в той степени, в какой мышление занято постижением общественных отношений, зависимо от интересов определенных социальных групп.

К. Мангейм, в развитие идей Э.Дюркгейма, уже дифференцирует знания, входящие в «точные» науки и общественные знания. Если первые, согласно К. Мангейму, развиваются сообразно своей внутренней логике, то общественные знания обусловлены социальной ситуацией, как и утопическими установками социальных групп, каждая из которых связывает общественный и духовный прогресс исключительно с реализацией собственных интересов. В силу этого подбираются и упорядочиваются эмпирические данные: выполняется социальный «заказ» группы (см.: $[8$, с. 178]).

Уже поэтому идеологическое знание не может не быть «превращенным», т. е. искаженным социально-групповым интересом и вынужденным преподносить его как интерес всего общества. Отсюда следует, что по отношению к общественному знанию предпочтительнее выдвигать критерии ценности, а не критерии истины, как это имеет место в «точных» науках. «Идеология тем и отличается от социальной науки, 
что, используя ее готовые выводы, выстраивает определенную модель действий и систему рационализации этих действий, отнюдь не обязательно совпадающих с научным выводами. Идеология обобщает в теоретических постулатах то, что в головах людей существует в форме разрозненных представлений о действительности, вооружает их этими постулатами как средством действия, а затем бросает всю силу логической доказательности, убеждений, чтобы выдать свой образ действий и мыслей за единственно верный» $[1$, с.4].

Несомненным фактом является наличие идеологического компонента во всех формах общественного сознания, в исторической практике развития общественного сознания идеология вплетается в разные духовные образования, «сращивается» с ними (см.: [3]). Но именно эта «вплетенность» в формы общественного сознания, а через них - в практическую деятельность людей, обеспечивает воздействие идеологии на ход исторического развития. Идеологические установки играют заметную роль в формировании стереотипов поведения, обычаев, обрядов, социальных традиций. Они, в конечном счете, оформляют облик общества, возвышая отдельных индивидов до степени субъектов социальных ценностей. Индивидуальное сознание при этом поднимается до уровня общественного через идеологическую составляющую.

К. Мангейм попытался проследить динамику идеологического содержания в процессе исторического развития и пришел к выводу, что искажение реальной действительности наличествует на всех этапах становления и функционирования идеологии. А это означает, что если обладание объективной истиной не дано ни одной социальной группе, то таковой истины идеология в себе и не содержит. Идеологический процесс не приводит к очищению человеческого знания от заблуждений, а потому критерии истинности или ложности к нему не применимы. Истина же, по К. Мангейму, - атрибут объекта, и она не зависит от форм вовлечения этого объекта в познавательные процедуры: истина представлена реальным процессом жизни, историческим субстратом, а не теоретическим конструкциями - таков лейтмотив всех мангеймовских исследований.

Но человеческое стремление к достижению истинного знания относительно реалий общественной жизни непреходяще, а потому этот процесс связывается чаще всего с преодолением узкогрупповых ориентаций, что находит свое выражение в «социологии знания»-общесоциальной теории, претендующей на относительную объективность в рамках определенной социальной структуры.

$\mathrm{C}$ нашей точки зрения, истоки идеологии социума следует искать 
именно в «социологии знания», первые исследовательские программы которой появляются в 20-30-х годах, а систематизированную форму приобретают в работах К. Мангейма «Социология знания» (1927 г.), «Идеология и утопия» $(1923$ г.) и Эрнста Грюнвальда «Проблема социологии знания» (1934г.). Это направление социологической науки, тесно соприкасающееся с социальной философией, положило начало интерпретации любых ментальных явлений как имманентных и равнозначных продуктов бытия социальности, социума. «Социология знания» предметом социального исследования делает лежащий на поверхности факт, что различные сферы познавательной жизни общества: философские системы, религиозные убеждения, законы науки, нравственные императивы, идеологические установки по-разному, иногда взаимоисключающим образом, постигают и описывают функции одного объекта - социума. Поэтому все разнообразие знания свидетельствует о разнообразии функций социума. «Социология знания», по К. Мангейму, исследует функциональную зависимость каждой интеллектуальной точки зрения от различных социальных групп, в действительности стоящих за нею» [8, с. 190]. Уже в первом приближении исследование показывает, что никакое знание не может претендовать на абсолютную истину, так как оно непременно находится в функциональной зависимости от конкретных социальных законов столь же конкретных социальных групп. Но если учесть, что все эти социальные группы составляют социум, то, в конечном счете, любое искаженное, «превращенное» знание становится составляющей знания социума.

Для обоснования данной посылки К. Мангейм рассматривает функциональные характеристики двух видов социально-искаженного знания - идеологии и утопии. Социально-групповую, «партикулярную» идеологию, направленную на критику идей и концепций иных идеологий, менее всего интересуют проблемы своей истинности и адекватности социальной реальности. Для нее достаточно обличения в искажении истины противной стороны. Этот прием весьма характерен, в частности, для коммунистической идеологии, даже в период ее формирования.

«Партикулярные» идеологии, по К. Мангейму, являются в сущности своей «ситуационально-трансцендентными и нереальными», т.е. несоответствующими «конкретно существующему, актуальному порядку» (см.: [9, с. 175]). При әтом он считает «истинной» идеологией идеологию «тотальную», т. е. детерминированную не социально-классовыми и даже не субъективно-психологическими факторами, а всей социально-духовной жизнью данного общества или исторической эпо- 
хи.

Утопии, по мысли К. Мангейма, суть сведенные воедино представления оппозиционных и угнетенных групп населения, озабоченных лишь мечтаниями о ниспровержении существующего социального порядка. Как и «партикулярные» идеологии, «утопии также трансцендентны по отношению к социальной ситуации, ибо они также ориентируют поведение в отношении тех моментов, которые данная ситуация не содержит, поскольку она понимается в данное время» $[9$, с. 176]. В этом сходство «партикулярной» идеологии и утопии. В их широком распространении К. Мангейм усматривает трагедию социальной мысли человечества: мысль детерминируется или социальной реальностью, которая уже не существует в действительности («партикулярная» идеология), или же социальной реальностью, которая имеет чисто виртуальную природу (утопия). «В любом случае реальная действительность скрывается и искажается» [9, с. 175].

Поскольку и утопия, и «партикулярная» идеология, все «точки зрения» и все «перспективы» в рамках этих феноменов «искажают реальную действительность», но в то же время входят в процесс постижения социума, то и «тотальная» идеология, идеология социума, возможна только как их постоянное отрицание на уровне взаимной критики. Истина не принадлежит социальным концепциям, она есть принадлежность объекта, социума. Социумом К. Мангейм обозначает тот «первичный субъект, который развертывается во времени, имеет свою истину в своем прогрессе» $[8$, с. 130$]$.

К. Мангейм разрабатывает программу замены «доктрины идеологии» «социологией знания», считая, что социум к этому уже готов, и «из простого учения об идеологиях возникает социология знания» $[9$, с.69]. Узкогрупповые точки зрения на социальную жизнь в условиях «открытых» (демократических или либеральных) обществ, образующие «открытые» идеологии, зачастую критикуются изнутри, учатся друг у друга, признают свою односторонность и потому открывают широкое поле для взаимных соглашений. Эти идеологии уже начали постигать свою ограниченность, свое несоответствие треб́ованиям времени. Им уже более присуща ориентация не на идеологические ценности, а на постижение «социологической истории духовной культуры», где приоритетным считаются «те факторы в мышлении, которые связывают его (человека. - О.3., А.3.) в каждом отдельном случае с социальным положением. Социологически ориентированная история духовной культуры будет призвана пересмотреть под новым углом зрения весь исторический процесс для нужд сегодняинего человека» 
(выделено нами. - О. 3., А. 3.) [9, с. 69]. Это есть основной результат, с одной стороны, становления «тотальной» идеологии в ходе конвергенции «партикулярных» идеологий, а с другой-сведение «тотальной» идеологии к «социологии знания». Обойтись без «тотальной» идеологии и заменить ее неким подобием естественнонаучного знания не представляется возможным в силу специфики социальной и духовной сфер: «имеются сферы мысли, в которых невозможно получить истину, существующую независимо от ценностей и позиции субъекта и не относящуюся к социальному контексту» $[9$, с. 70$]$.

Вполне естественно, что в центре подобной программы оказывается интеллигенция, лично заинтересованная и склонная к получению истинного знания о социальной действительности. Социальная обусловленность этой группы исключительно слаба и основой ее самоидентификации является образование. «Хотя интеллигенты по своему происхождению слишком дифференцированы, чтобы можно было рассматривать их как единый класс, существует тем не менее одна объединяющая социологическая связь между всеми группами интеллигентов, а именно образование, которое удивительным образом связывает их воедино. Само участие в общем процессе образования во все возрастающей степени имеет тенденцию подавлять различия, доставшиеся им от рождения, различия в общественном положении, профессии или богатстве, и объединять людей на базе того образования, которое они получили» $[9$, с. 138$]$.

Все это может свидетельствовать в пользу допущения относительно независимого от социальных предрассудков, «неприверженного» мышления и «сфокусированной созерцательности» интеллигенции. Но из этого следует, что образование сводит к минимуму ту односторонность и предвзятость в понимании социальной действительности, которая свойственна индивидам в силу их социального происхождения, воспитания, имущественного положения и т. д. Именно образование, по K. Мангейму, способно обеспечить такое понимание реальности, которое характеризуется многосторонностью, универсальностью, а интеллигенция представляет слой, способный и предназначенный для разработки «предельно полного синтеза различньх тенденций эпохи» $[9$, c. 137]. В этом плане «социология знания» не отвергает возможности «объективного» социального знания, способного аккумулироваться в «тотальную» идеологию социума. Из работ К. Мангейма следует, что в «тотальной» идеологии от прежних идеологий остается лишь ценностный аспект, возводимый в ранг метасоциальных ценностей.

В тоталитарном обществе в ранг непреходящих социальных ценно- 
стей возводятся стадность, социальная организация, рационализм. И действительно, в едином монолитном коллективе, одержимом общей (хотя бы сиюминутной) целью, а тем более перспективой построить социально-однородное коммунистическое общество, индивид чувствует себя комфортно и уверенно, осознает собственную силу как часть общей силы коллектива. Чувство организации и социальной иерархии атрибутивное качество социального бытия индивида в тоталитарном обществе. Недаром памятник Артему (Ф.А. Сергееву) в Славянске венчает фраза: «Зрелище неорганизованных масс для меня невыносимо».

Социум существует как единая целостная система, состоящая из подсистем - больших и малых социальных групп, из индивидов. Социальная группа - это система взаимодействия индивидов, но в то же время социальная группа относительно самостоятельна, специфична, ценна не только для общества и индивида, но и для самой себя. «Стабильность существования любой социальной группы на социально-психологическом уровне определяется ощущением (первоначально бессознательным) внутренней общности, чувством „мы“, за границей которого-,они“» [5, с. 27]. Идеология оформляет систему групповых ценностей, в которой на первом месте всегда и неизменно остается цель самосохранения группы. И это находит отражение в специфике идеологии, что удачно описывает О.Н. Козлова: «Атрибутивным свойством идеологии является интровертность, центростремительность этих специфических систем знания. И в этом, безусловно, заключена их потенциальная социальная опасность для общества и индивида. Ведь в системе идеологически выстроенных групповых ценностей самосохранение вполне может трактоваться расширительно, оправдывать әкспансию данной группы в отношении других групп, в отношении „не нас" (все, кто не с нами, тот против нас, тот для нас угроза, которую надо ликвидировать ради самосохранения). Подобная экспансия группы (нации, класса и др.) и осуществлялась не раз в полном соответствии с ее идеологией. Это, в свою очередь, вело к изменению в духовной жизни оппозиции, компенсирующей свое поражение ощущением морального превосходства, приступающей к борьбе с групповым эгоизмом, а заодно и с групповьм самосознанием, с идеологией вообще как ненаучным, ложным сознанием» [5, с. 27].

Провозглашение же приоритета общечеловеческих ценностей над групповыми представляется необоснованным. Ибо полноценная идеологическая жизнь связана с тем, что именно плюрализм идеологических ценностей лежит в основе механизма, сдерживающего манипуляцию власти. Отказавшись от групповых идеологий, общество не может 
отказаться от выполнения тех свонх функций, которые традиционно осуществлялись конкретными социальными группами. Если не развивается групповое сознание, групповая идеология, то поведение членов данной группы становится непредсказуемым, а их притязания - неадекватными.

Все вышеизложенное не имеет прямого отношения к апологетике групповых идеологий. Ведь идеологическое знание, по определению, не может быть ни научным, ни истинным, ни объективным. Это знание однозначно субъективное, обслуживающее потребности, устремления, идеалы социальной группы. Но именно такое знание, систематизированное идеологией, позволяет вырабатывать субъективные образы желаемого, благого. Объективизация же этих образов достигается в диалоге различных идеологий. Тем не менее, функционирование социально-групповых идеологий способствует постижению социальной реальности как принципиально доступной человеческому познанию.

\section{1 Литература}

[1] Aнтонович И.И. Социодинамика идеологий.-Минск: Навука і тэхніка, 1995.

[2] Дгоркеейм Э. О разделении общественного труда. Метод социологин.- М.: Наука, 1991.

[3] Заздравиов А.П. Мировоззрение как социокультурный феномен. Харьков, 2000.

[4] Гванов В.П. Життєвий світ особи // Філософська думка. - 1982. № $1 .-$ C. $15-17$.

[5] Козлова О.Н. Развитие идеологий и социальные конфликты // Социс. - 1993. - № 4. - С. 25-29.

[6] Lemberg E. Antropologie der ideologischen Sycteme.-Weinheim, 1997.

[7] Luhman N. Politische Planung. - Westdeutsche Verlag. - 1985.

[8] Mannheim K. Essays in the Sociology of Knowledge. - London, 1990.

[9] Mannheim K. Ideology and Utopia.-London, 1988. 